\title{
Grupos locales y acumulación de capital en el sector de electrónica de consumo en Argentina (2003-2014)
}

Local Groups and the Accumulation of Capital in the Consumer Electronics Sector in Argentina (2003-2014)

Grupos locais e acumulação de capital no setor eletrônico de consumo na Argentina (2003-2014)

Joel Rabinovich *

DOI: https://doi.org/10.19053/01203053.v37.n65.2018.5899

Fecha de recepción: 3 de marzo de 2017

Fecha de aprobación: 13 de octubre de 2017

* Mg. in Political Economy, Macroeconomics and Finance. Doctorando en Economía en Université Paris XIII Sorbonne-Paris-Cité, CEPN (CNRS, UMR 7234), París, Francia. Correo electrónico: joel.rabinovich@edu.univ-paris13.fr - (D) orcid 0000-0002-9175-0848 


\section{Resumen}

En un contexto de extranjerización de varias de las empresas de capitales argentinos de mayor facturación, una serie de grupos de capitales locales de menor tamaño relativo, vinculados a la producción o comercialización de electrónica de consumo, obtuvieron altas tasas de crecimiento a partir de 2003. El presente trabajo tiene como objetivo explicar este fenómeno desde el concepto de los "ámbitos privilegiados de acumulación". Haciendo uso de informes de cámaras empresariales y memorias de los grupos seleccionados, así como también de información macro y mesoeconómica, el artículo delimita las principales características de este ámbito privilegiado de acumulación, ilustra cómo los grupos adaptaron su dinámica productiva y financiera para beneficiarse de él y demuestra el peso decisivo que tiene actualmente para la rentabilidad de estos grupos.

Palabras clave: organización industrial y cambio estructural, empresas transnacionales, inversión extranjera, industria electrónica.

Clasificación JEL: L16, F23, L63. 


\section{Abstract}

In a context of the foreignization of many of the largest Argentinian businesses, a number of comparatively smaller local business groups related to the production or commercialization of consumer electronics have obtained high rates of growth since 2003. The objective of this article is to explain this phenomenon by means of the concept of "privileged areas of accumulation". Using reports from different business associations and the memories of selected groups, as well as macro and mesoeconomic information, this article shows the main characteristics of this privileged area of accumulation, illustrating how the business groups adapted their productive and financial dynamics in order to benefit from it and demonstrating its decisive importance for the profitability of these groups.

Keywords: industrial structure and structural change, transnational enterprises, foreign investment, electronics industry. 


\section{Resumo}

Em um contexto de estrangeirização de várias das maiores empresas argentinas, uma série de grupos locais de menor tamanho relativo, vinculados à produção e/ou comercialização de eletrônica de consumo, obtiveram elevadas taxas de crescimento a partir de 2003. O objetivo deste artigo é explicar este fenômeno a partir do conceito de "âmbitos privilegiados de acumulação". Utilizando relatórios de diferentes câmaras empresariais e grupos selecionados, bem como informações macro e mesoeconômicas, o artigo apresenta as principais características deste âmbito privilegiado de acumulação, ele ilustra como os grupos empresariais adaptaram suas dinâmicas produtivas e financeiras para se beneficiar dela e demonstra a sua importância decisiva para a rentabilidade destes grupos.

Palavras-chave: Organização industrial e mudança estrutural, Empresas transnacionais, Investimento estrangeiro, Indústria eletrônica. 


\section{INTRODUCCIÓN}

Los llamados "grupos económicos" ocupan un papel protagónico en la historia económica reciente de los países en desarrollo en general y de América Latina en particular (Jones \& Colpan, 2010) ${ }^{1}$. Debido a esto, el estudio de este tipo de organización empresarial ha ocupado un rol destacado, en forma temprana, dentro de la historia económica y de empresas en los distintos países latinoamericanas, como lo atestiguan Dahse (1979) en Chile, Fishlow (1972) en Brasil, Jacobs (1981) en México, Silva-Colmenares (1977) en
Colombia y Schvarzer (1978) en Argentina. Schneider (2009) señala que los grupos económicos pertenecientes a Latinoamérica tradicionalmente exhibieron cuatro características: alta diversificación, control jerárquico de las empresas del grupo, elevado peso en la economía, así como también la propiedad y dirección familiar. Siguiendo a Garrido y Peres (1998), las reformas estructurales tendientes a la liberalización económica y política en los años 90 representaron un desafío para estas organizaciones, en cuanto llegaron a su posición dominante bajo el amparo de regímenes de industrialización por

\footnotetext{
${ }^{1}$ Seguiremos la definición de Khanna y Yafeh (2007), quienes definen a un grupo económico como un conjunto de firmas legalmente independientes que operan en diversas ramas, frecuentemente no relacionadas entre sí, que se conforman como una unidad a partir de lazos formales (por ejemplo, propiedad común de sus acciones) o informales (pertenecen a una misma familia).
} 
sustitución de importaciones (ISI) ${ }^{2}$. Según estos mismos autores, ex ante se esperaba que la mayor competencia haría que los grupos se focalizaran en una determinada industria. Asimismo, en tanto los mercados de acciones se volvían más globales, los mercados locales de capitales se desarrollaban y mayor cantidad de grupos emitían acciones, el papel de las familias originales se diluiría. Sin embargo, estas expectativas no se cumplieron en la mayor parte de los países latinoamericanos, como lo reconocen los propios autores y demuestran recientes estudios para el caso ecuatoriano (Martínez, 2017), brasileño (Aldrighi \& Postali, 2010) o chileno (Lefort, 2010), entre otros. En otros países, tales como Perú y Argentina, no obstante, los grupos tuvieron un peor desempeño relativo (Schneider, 2009, p. 559).

En el caso argentino, con las sanciones de la Ley 23696 (de Reforma del Estado) y 23697 (de Emergencia Económica) en 1989, el Estado perdió muchas de las herramientas utilizadas para favorecer a los grupos locales. Si bien se dio una serie de medidas para contrarrestar esto último y lograr que los grupos apoyaran la nueva política económica (especialmente las privatizaciones de empresas públicas), los trabajos sobre este período (Bisang, 1998; Castellani \& Gaggero, 2012; Fracchia, Mesquita \& Quiroga, 2010; Manzanal \& Rofman, 1989; Rabinovich \& Giliberto, 2015) muestran cómo los grupos locales debieron adaptar sus estrategias de crecimiento en el nuevo contexto. Empero, la recesión y posterior crisis de finales de la década, la intensificación en el desembarco de empresas extranjeras, las sucesivas crisis financieras junto con la ausencia de herramientas de política por parte del Estado tuvieron como consecuencia la venta de una serie de empresas pertenecientes a grupos locales a manos extranjeras. La magnitud de este fenómeno ha sido tal que concentró buena parte de los estudios relacionados con los grupos locales, en tanto la extranjerización se mantuvo durante buena parte del período posterior a la crisis de convertibilidad $^{3}$, es decir, incluso en un contexto de crecimiento económico (Manzanelli \& Schorr, 2012; Wainer \& Schorr, 2014). Otros trabajos se han focalizado en su contracara, esto es, en aquellos grupos que han superado exitosamente este período, sea consolidándose en determinados nichos locales o bien convirtiéndose

\footnotetext{
2 Las reformas consistieron, generalmente, en las privatizaciones de empresas públicas, la eliminación de las restricciones a la inversión extranjera directa, la disminución de los aranceles a la importación, entre otras. Desde ya, la magnitud del desafío para los grupos dependió de la situación concreta de cada país, así como también de la forma en que fueron aplicadas las políticas neoliberales.

3 Cuando hablamos de "convertibilidad" nos referimos al período comprendido entre los años 1991 y 2001 , en el cual el peso argentino tuvo un tipo de cambio fijo por ley con el dólar estadounidense.
} 
en jugadores internacionales, tanto a nivel regional como mundial. Tal es el caso de Techint (Artopoulos, 2006, 2009) o Arcor (Kosacoff, Barbero, Forteza, Porta \& Stengel, 2001; Wainer \& Schorr, 2006), por citar algunos ejemplos.

No obstante, estos no han sido los únicos hechos relevantes que se dieron en la última década en lo relativo a grupos económicos locales. A la par que algunos conglomerados que supieron ocupar lugares de privilegio en la economía argentina pasaban a manos extranjeras y otros consolidaban sus posiciones en el mercado local o mundial, una serie de grupos de capitales locales, de menor tamaño, aparecieron en escena avanzando varios lugares dentro del ranking de empresas de mayor facturación. Buena parte de lo escrito sobre estos grupos se concentra en sus relaciones con el gobierno de turno, principalmente en la prensa especializada, como en el caso del trabajo periodístico de Rafele y Fernández (2013). En el ámbito académico, los trabajos son más bien incipientes, destacándose el libro de Gaggero, Schorr y Wainer (2014) o el reciente artículo de Schorr y Gaggero (2016). Si bien en estos trabajos se hace referencia a parte de los nuevos grupos, es en el marco de un diagnóstico general de las grandes empresas que operan en Argentina. Hasta el momento, solo Rabinovich (2017) analiza este conjunto en su totalidad aunque de forma general.

El presente artículo busca saldar parcialmente esta deuda, explicando cómo fue que en un contexto de extranjerización de las principales empresas que operan en Argentina, una serie de grupos de capitales locales, de menor tamaño relativo ${ }^{4}$, logró crecer en facturación. Nos concentraremos, puntualmente, en los grupos vinculados a la fabricación (y también venta en algunos casos) de electrónica de consumo. Para explicar su derrotero, acudiremos al concepto de ámbito privilegiado de acumulación (APA), propuesto por Castellani (2009) para definir, originalmente, el conjunto de distintas políticas estatales generadas para apoyar a los grupos locales en Argentina a fines de la década del 60 , y mantenidas a lo largo de los 70 y $80^{5}$. El trabajo tiene como objetivo, entonces, analizar las distintas características y condiciones de posibilidad de este APA que definiremos, grosso modo, como condiciones de demanda

\footnotetext{
${ }^{4}$ Que definimos como aquellos que se encontraban por fuera de las 100 empresas de mayor facturación en 1997.

${ }^{5}$ Se refiere concretamente a grandes planes de obras públicas, establecimiento de regímenes de "compre nacional", promoción de grandes emprendimientos industriales financiados o subsidiados por el Estado y políticas de promoción industrial. Para Castellani (2009), los APA son generados y sostenidos en el marco de un entramado de relaciones entre actores públicos y privados, que permiten obtener ganancias extraordinarias para las empresas que operan en él.
} 
y condiciones de oferta. Se usan, para ello, estadísticas de cuentas nacionales e informes de cámaras empresariales. Se estudiarán, asimismo, las estrategias de algunos grupos puntuales que se beneficiaron del mismo utilizando, como fuentes, sus respectivas memorias y estados contables, páginas de internet e información de prensa especializada (Revista Mercado) y no especializada (diarios de circulación masiva). A partir de ello se podrá verificar el grado de dependencia del APA por parte de los grupos que operan en él.

La estrategia metodológica, entonces, articula dinámicas macro y mesoeconómicas junto al accionar individual de los grupos que, por un lado, adaptaron sus estrategias de producción en función de los beneficios del APA y, por el otro, pugnaron, a partir de sus respectivas cámaras empresariales, por mantener y aumentar este ámbito. Observaremos que esto dio como resultado la conformación de un APA caracterizado por:

a. Ser aquel que recibe la mayor parte de los fondos públicos destinados a regímenes de promoción.

b. Depender fuertemente de la demanda final de los hogares por sobre la del sector público. c. Contar con un respaldo sostenido por parte del gobierno, el cual, frente a situaciones de disputa con otras fracciones empresarias, decidió favorecer y profundizar este régimen.

d. Tener un acceso limitado, lo cual imposibilitó que otras empresas se favorecieran del mismo.

Los beneficios asociados a este APA han sido tales que permitieron un marcado ascenso de una serie de grupos locales. Nos referimos a los casos de NewSan, Mirgor-Caputo, Garbarino, Frávega y Megatone, los cuales pasaron de los puestos $769,407,179,347$ y 280 en el ranking de empresas de mayor facturación en el año 2002 a los puestos $76,86,56,63$ y 77 respectivamente, en el año $2014^{6}$.

El artículo se organiza de la siguiente forma. La sección siguiente estudiará las condiciones de demanda: el aumento de consumo junto al aumento del crédito al consumo. A continuación se hará lo propio con las condiciones de oferta: el Régimen de Promoción Económica de la Provincia de Tierra del Fuego y la capacidad para mantener y potenciar el APA de las empresas agrupadas en la cámara Afarte (Asociación de Fábricas Terminales Eléctricas). La

\footnotetext{
${ }^{6}$ La metodología de selección de casos puede consultarse en Rabinovich (2017).
} 
sección siguiente se concentrará en las trayectorias particulares de los grupos haciendo un breve repaso de su evolución productiva y financiera reciente. Por último, se darán algunas conclusiones.

\section{CONDICIONES DE DEMANDA}

\section{Crecimiento del consumo en la última década}

En primer término, se focalizará en las características que presentó la demanda de este tipo de mercancías a lo largo de la última década. Como puede verse en la Figura 1, en todos los años en que la demanda global creció, el consumo fue el componente que más aportó a ese crecimiento. De hecho, en la Figura 2 podemos observar que salvo para los años 2009 y 2012 (años de recesión en que la inversión fue la que explicó la mayor parte de la caída) su contribución nunca fue menor al $40 \%$. Vemos también cuatro años en los que su contribución fue mayor al $60 \%$ (si bien el 2014 se debe a una caída) con el caso extremo del año 2013, en el cual crecimiento de la demanda global es prácticamente el mismo que el del consumo.

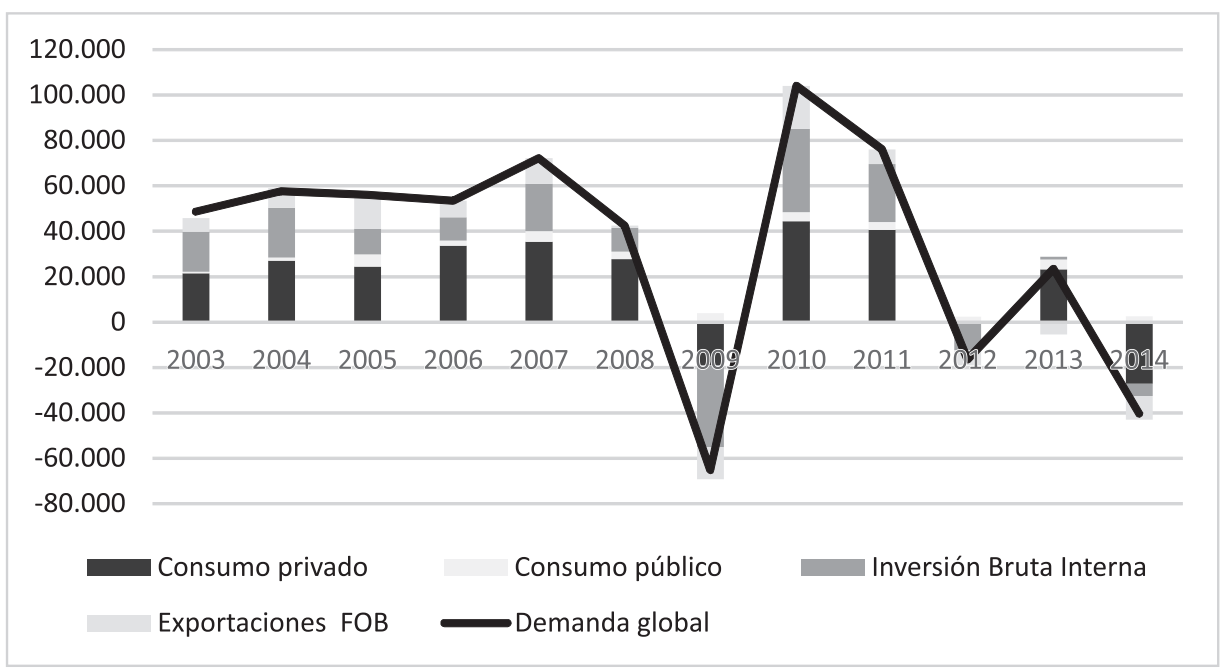

Figura 1. Contribución a la variación de la demanda global, 2003-2014.

Millones de pesos de 2004.

Fuente: elaboración propia con base en Instituto Nacional de Estadísticas y Censos (Indec). 




Figura 2. Variación del consumo privado sobre la variación de la demanda global, 2003-2014. Valores en porcentajes.

Fuente: elaboración propia con base en Indec.

Por su parte, las figuras 3 y 4 son útiles para identificar cuáles fueron los rubros en los que se canalizó este aumento en el consumo privado. $\mathrm{Si}$ bien no dan cuenta de la descomposición total del mismo, muestran que tanto en los supermercados como en los centros comerciales el rubro de mayor crecimiento en el período seleccionado ha sido el de "electrónicos y artículos para el hogar" y "electrónicos, CD y electrodomésticos" respectivamente. Según datos del Indec (2015c, 2015a), en los supermercados las ventas de estos artículos pasaron del $3.43 \%$ en 2003 al $7.04 \%$ en 2013 como porcentaje del total de ventas, mientras que en los centros comerciales aumentaron del $9.7 \%$ en 2003 al $19.3 \%$ en 2013.

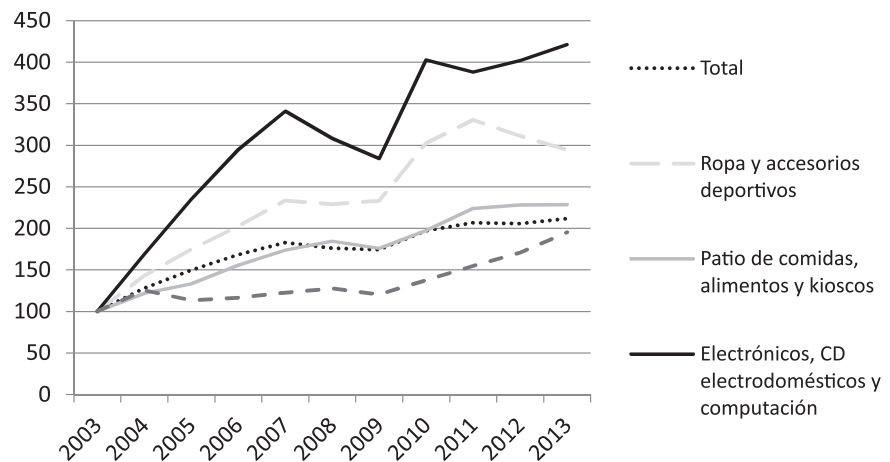

Figura 3. Evolución anual de las ventas por grupos de artículos en centros comerciales a precios constantes, 2003-2013. Índice 2003 $=100$

Fuente: elaboración propia con base en la Encuesta de Centros de Compras (centros comerciales) - (Indec, 2015a) 


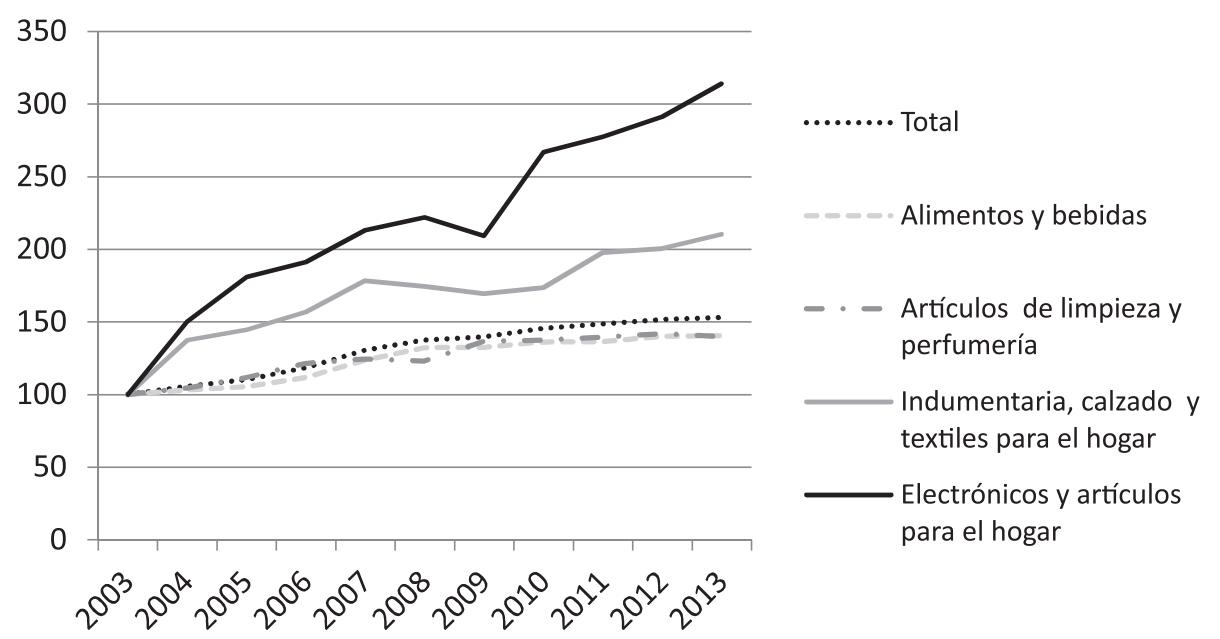

Figura 4. Evolución anual de las ventas por grupos de artículos en supermercados a precios constantes, 2003-2013. Índice 2003 $=100$

Fuente: elaboración propia con base en la Encuesta de Supermercados (Indec, 2015c)

Uno de los factores que posibilitaron la recuperación del mercado fue la renovación tecnológica, con productos que se popularizaron y crecieron rápidamente, tales como cámaras fotográficas digitales, reproductores de DVD (Sainz, 2005). Luego se agregarán otros, tales como notebooks, netbooks y teléfonos celulares. Asimismo, la renovación tecnológica estuvo vinculada a la crisis económica, la cual dio como resultado un retraso en el consumo. Según Enrique Germano, director comercial del grupo Garbarino en 2005, "entre 2001 y 2002 las ventas estuvieron congeladas. Sólo en 2003 empezaron a recuperarse y el año pasado marcaron récords. Hubo un retraso tecnológico muy fuerte y ahora la gente quiere renovar" (García, 2005).

Por último, vale la pena señalar que las ventas de electrodomésticos en centros comerciales y supermercados son mucho menores que aquellas que se dan en casas especializadas en ese rubro (tales como Frávega, Megatone y Garbarino, que se analizarán en la sección que se focaliza en los grupos). Lamentablemente, la encuesta del Indec de este tipo de establecimientos solo está disponible para unos pocos años, por lo cual solo en ese breve lapso de tiempo se pueden comparar las ventas de electrodomésticos en los tres lugares (Tabla 1). 
Tabla 1. Ventas de electrodomésticos y artículos para el hogar en supermercados, centros comerciales y comercios especializados en Gran Buenos Aires, 2009-2013. Valores en unidades

\begin{tabular}{|l|c|c|c|c|c|c|}
\hline \multirow{2}{*}{ Año } & \multicolumn{2}{|c|}{ Ventas en supermercados } & \multicolumn{2}{|c|}{$\begin{array}{c}\text { Ventas en centros } \\
\text { comerciales }\end{array}$} & \multicolumn{2}{|c|}{$\begin{array}{c}\text { Ventas en comercios de electro- } \\
\text { domésticos y } \\
\text { artículos para el hogar }\end{array}$} \\
\cline { 2 - 7 } & Cantidad & $\begin{array}{c}\text { Variación } \\
\text { interanual }\end{array}$ & Cantidad & $\begin{array}{c}\text { Variación inte- } \\
\text { ranual }\end{array}$ & Cantidad & $\begin{array}{c}\text { Variación inte- } \\
\text { ranual }\end{array}$ \\
\hline $\mathbf{2 0 0 9}$ & 2570384 & - & 1327743 & - & 9578415 & - \\
\hline $\mathbf{2 0 1 0}$ & 4051529 & $57.62 \%$ & 2329093 & $75.42 \%$ & 14755219 & $54.05 \%$ \\
\hline $\mathbf{2 0 1 1}$ & 5269399 & $30.06 \%$ & 2809420 & $20.62 \%$ & 17960525 & $21.72 \%$ \\
\hline $\mathbf{2 0 1 2}$ & 6849233 & $29.98 \%$ & 3598537 & $28.09 \%$ & 21943968 & $22.18 \%$ \\
\hline $\mathbf{2 0 1 3}$ & 9266615 & $35.29 \%$ & 4733301 & $31.53 \%$ & 29214258 & $33.13 \%$ \\
\hline
\end{tabular}

Fuente: elaboración propia con base en Encuesta de Comercios de Electrodomésticos y Artículos para el Hogar (Indec, 2015b)

Como conclusión, se observa que los grupos productores o comercializadores (o ambos) de electrónica de consumo tuvieron, en la última década, un contexto particularmente favorable en la demanda puntual de sus productos. En el siguiente apartado se estudiará cómo este incentivo de demanda se vio aumentado por la posibilidad de financiar las compras mediante créditos.

\section{Crecimiento del crédito al consumo}

El crédito al consumo ha jugado un rol fundamental para el crecimiento de la demanda de este tipo de bienes, tanto en los momentos de expansión como en los de crisis. La venta de electrodomésticos y electrónica en cuotas, por su parte, no es patrimonio exclusivo de las casas especializadas, sino que los supermercados también fueron adoptando la modalidad. La Tabla 2 ilustra el peso cada vez mayor que han tenido los préstamos personales y de tarjeta de crédito (ambos conforman el crédito al consumo) dentro de los préstamos totales al sector privado. 
Tabla 2. Préstamos al sector privado en monedas nacional y extranjera, 1999-2014. Valores en porcentajes

\begin{tabular}{|c|c|c|c|c|}
\hline Fechas & $\begin{array}{c}\text { Créditos } \\
\text { hipotecarios }\end{array}$ & $\begin{array}{c}\text { Préstamos } \\
\text { personales }\end{array}$ & $\begin{array}{c}\text { Tarjetas de } \\
\text { crédito }\end{array}$ & Otros \\
\hline $\mathbf{3 0 / 1 2 / 1 9 9 9}$ & 24.32 & 8.41 & 5.89 & 61.38 \\
\hline $\mathbf{2 8 / 1 2 / 2 0 0 0}$ & 27.12 & 8.78 & 6.54 & 57.56 \\
\hline $\mathbf{3 1 / 1 2 / 2 0 0 1}$ & 31.56 & 9.46 & 7.43 & 51.55 \\
\hline $\mathbf{3 1 / 1 2 / 2 0 0 2}$ & 32.61 & 7.32 & 6.38 & 53.69 \\
\hline $\mathbf{3 1 / 1 2 / 2 0 0 3}$ & 30.17 & 8.09 & 8.13 & 53.61 \\
\hline $\mathbf{3 1 / 1 2 / 2 0 0 4}$ & 22.90 & 11.00 & 8.90 & 57.20 \\
\hline $\mathbf{3 0 / 1 2 / 2 0 0 5}$ & 16.54 & 13.77 & 10.53 & 59.16 \\
\hline $\mathbf{2 9 / 1 2 / 2 0 0 6}$ & 13.66 & 17.40 & 10.36 & 58.58 \\
\hline $\mathbf{2 8 / 1 2 / 2 0 0 7}$ & 13.61 & 19.86 & 11.03 & 55.50 \\
\hline $\mathbf{3 1 / 1 2 / 2 0 0 8}$ & 14.45 & 21.18 & 12.50 & 51.87 \\
\hline $\mathbf{3 1 / 1 2 / 2 0 0 9}$ & 13.00 & 21.15 & 13.92 & 51.93 \\
\hline $\mathbf{3 0 / 1 2 / 2 0 1 0}$ & 10.68 & 20.27 & 14.76 & 54.29 \\
\hline $\mathbf{3 0 / 1 2 / 2 0 1 1}$ & 9.74 & 20.18 & 15.11 & 54.98 \\
\hline $\mathbf{3 1 / 1 2 / 2 0 1 2}$ & 9.54 & 19.81 & 16.38 & 54.28 \\
\hline $\mathbf{3 0 / 1 2 / 2 0 1 3}$ & 9.00 & 19.84 & 18.11 & 53.05 \\
\hline $\mathbf{3 0 / 1 2 / 2 0 1 4}$ & 8.16 & 19.71 & 20.69 & 51.44 \\
\hline
\end{tabular}

Fuente: elaboración propia con base en Banco Central de la República Argentina.

La importancia del crédito es corroborada por actores del sector, tales como Guillermo Olsen, director de marketing del grupo Frávega en 2004, quien afirmaba que "[e]l buen momento que vive el negocio se debe en gran parte a las compras con tarjeta, ya que en nuestro caso las ventas financiadas en más de tres cuotas representan el $70 \%$ de las operaciones" (Sainz, 2004).

De hecho, frente a la crisis de 2009 , en la cual caen las ventas, fueron las cadenas de electrodomésticos más 
grandes y con presencia en la capital del país (tales como Garbarino o Frávega) aquellas que salieron mejor paradas comprando en muchos casos comercios independientes y firmas de menor tamaño. Estas últimas fueron las que sufrieron la disminución en las ventas, ya que sus clientes muchas veces no tenían acceso a tarjetas tradicionales, la principal fuente para comprar en cuotas. Juan Manuel Aragonés, director comercial del grupo Garbarino en 2009, afirmaba que: "[h]oy estamos facturando en pesos lo mismo que en 2008, lo que significa que estamos ganando participación de mercado, y el gran motor en las ventas es la posibilidad que tenemos de seguir ofreciendo las cuotas sin intereses" (Sainz, 2009b).

Así, la posibilidad de ofrecer compras en cuotas fue también determinante a la hora de permitir a estos grupos concentrar parte del mercado. Si bien el Estado tuvo herramientas para evitar esto (sobre todo a partir de la estatización de los fondos jubilatorios a fines de 2008), en la práctica la política frente al sector se focalizó en mantener los créditos al consumo y disminuir la tasa de interés para la compra de electrodomésticos y electrónica de consumo (La Nación, 2008).

Habiendo repasado las condiciones de demanda (el aumento del consumo y el crédito al consumo), en el siguiente apartado se hará lo propio con las condiciones de oferta. Nos referimos, más precisamente, al Régimen de Promoción de Tierra del Fuego, y también estudiaremos la capacidad para mantener y profundizar el APA en contextos adversos.

\section{CONDICIONES DE OFERTA}

\section{Régimen de Promoción Econó- mica de la Provincia de Tierra del Fuego}

Un común denominador que caracteriza a los grupos analizados es el hecho de que sus empresas se vieron alcanzadas por los beneficios otorgados bajo el Régimen promocional de Tierra del Fuego. Este Régimen ha sido objeto de numerosos estudios que suelen concentrarse en el perfil de producción llevado a cabo en la isla, el tipo de especialización asociado, así como también su impacto tributario y comercial (Centro de Estudios para la Producción, 2001; Filadoro, 2007; Garófalo, 2004; Nochteff, 1984; Passetti, 2014; Schorr \& Porcelli, 2014). No es nuestra intención hacer aportes novedosos en ninguna de estas dimensiones, sino señalar en qué sentido el Régimen operó para posibilitar el APA que estamos analizando.

En la compilación de normas realizada por Garófalo (2004) se detalla un conjunto de leyes, resoluciones y decretos que comienzan con la Ley 19640 que en 1972 estableció un régimen fiscal y 
aduanero para la región con objetivos de carácter geopolítico y de poblamiento de la zona. Allí se define un "Área Franca" (la parte del territorio que no pertenece a la Isla Grande) y un "Área Aduanera Especial” (la Isla Grande), y determina un subrégimen industrial para ella, en el cual se otorgan beneficios fiscales y aduaneros para promover las actividades manufactureras.

Entre los beneficios más importantes están la exención del pago de todo impuesto nacional correspondiente a hechos, actividades u operaciones relacionadas en aquel territorio. Esto es, la exención del impuesto a las ganancias y del pago del IVA a la compra de insumos y venta del bien final. Asimismo, las importaciones y exportaciones quedaban exentas de cualquier requisito cambiario, a la vez que se brindaban beneficios para la importación de bienes de capital o materias primas afectadas a actividades industriales del área y exención total de derechos de exportación. Tal como lo señalara ya Azpiazu (1988), los resultados relativos al perfil de especialización de la isla y de desarrollo industrial fueron pobres, en cuanto estimulaban un carácter de armaduría y mercado-internista.

No obstante, este subrégimen industrial se mantendría hasta el año 1989, cuando, a partir de la Ley 23 697 de "Emergencia Económica", se suspenden todos los regímenes de promoción industrial por un plazo de 60 días (Garófalo, 2004). Esta ley implicó la imposibilidad de presentar nuevos proyectos hasta que el Decreto $479 / 1995$ estableció un esquema de reemplazo de producciones previas por nuevos bienes en tanto no desplacen fabricaciones del territorio continental. Será recién en 2003, con el Decreto 490, que el esquema se vuelve a abrir autorizando la radicación de nuevas empresas (algo que volvería a suceder en 2010 y 2011) e incorporando artículos puntuales (Garófalo, 2004).

Finalmente, en el año 2009 la Ley 26 539 incrementó los gravámenes para una serie de productos importados de electrónica de consumo, a la vez que el Decreto 252/09 redujo la parte alícuota de impuestos internos para estos mismos bienes producidos en Tierra del Fuego (Schorr \& Porcelli, 2014). La combinación de estas últimas medidas tuvo, inmediatamente, beneficios de gran magnitud para las empresas radicadas en la isla,

La combinación de la Ley 26539 [...] y el Decreto 252/2009 [...], se ha transformado en una herramienta fundamental para la industria que permitirá, a las empresas radicadas en esa provincia, recuperar producciones que la competencia importada habían transformado en antieconómicas como así también iniciar la producción nacional 
de una variedad de productos que eran hasta entonces inviables económicamente. (NewSan S.A., 2009, p. 4)

La promoción de la Ley 26539 junto al Decreto 252/09 demostró la importancia de este Régimen para el Estado nacional. Esto puede corroborarse en la Tabla 3, que indica que, a lo largo de los últimos años, las medidas asociadas al Régimen de Promoción Económica de la Provincia de Tierra del Fuego pasaron a concentrar más de tres cuartas partes del total de los gastos tributarios originados en regímenes de promoción económica.

Tabla 3. Gastos tributarios originados en regímenes de promoción económica, 2003-2013. Valores en millones de pesos corrientes

\begin{tabular}{|c|c|c|c|c|c|c|c|}
\hline \multicolumn{2}{|c|}{$\begin{array}{c}\text { Gasto } \\
\text { tributario }\end{array}$} & $\begin{array}{l}\text { Libera- } \\
\text { ción IVA } \\
\text { compras y }\end{array}$ & $\begin{array}{c}\text { Exención } \\
\text { impuesto } \\
\text { a las } \\
\text { ganancias }\end{array}$ & $\begin{array}{c}\text { Exención } \\
\text { derechos } \\
\text { de } \\
\text { importa- } \\
\text { ción sobre }\end{array}$ & $\begin{array}{l}\text { Alícuota } \\
\text { reducida } \\
\text { impuestos } \\
\text { internos } \\
\text { sobre }\end{array}$ & $\begin{array}{c}\text { Gasto total en } \\
\text { promoción econó- } \\
\text { mica de } \\
\text { Tierra del }\end{array}$ & $\begin{array}{l}\text { Gasto total } \\
\text { en promo- } \\
\text { ción }\end{array}$ \\
\hline \multirow{2}{*}{2003} & Valor & 505.07 & 50.00 & 197.76 & - & 752.83 & 2266.371 \\
\hline & $\%$ & $22.29 \%$ & $2.21 \%$ & $8.73 \%$ & - & $33.22 \%$ & \\
\hline \multirow{2}{*}{2004} & Valor & 601.45 & 50.00 & 197.09 & - & 848.54 & 2238.578 \\
\hline & $\%$ & $26.87 \%$ & $2.23 \%$ & $8.80 \%$ & - & $37.91 \%$ & \\
\hline \multirow{2}{*}{2005} & Valor & 726.53 & 60.00 & 235.12 & - & 1021.65 & 2801.35 \\
\hline & $\%$ & $25.93 \%$ & $2.14 \%$ & $8.39 \%$ & - & $36.47 \%$ & \\
\hline \multirow{2}{*}{2006} & Valor & 907.63 & 70.80 & 351.21 & - & 1329.63 & 3287.696 \\
\hline & $\%$ & $27.61 \%$ & $2.15 \%$ & $10.68 \%$ & - & $40.44 \%$ & \\
\hline \multirow{2}{*}{2007} & Valor & 1153.16 & 90.27 & 457.70 & - & 1701.14 & 4455.807 \\
\hline & $\%$ & $25.88 \%$ & $2.03 \%$ & $10.27 \%$ & - & $38.18 \%$ & \\
\hline \multirow{2}{*}{2008} & Valor & 1464.68 & 285.98 & 469.54 & - & 2220.2 & 4545.097 \\
\hline & $\%$ & $32.23 \%$ & $6.29 \%$ & $10.33 \%$ & - & $48.85 \%$ & \\
\hline \multirow{2}{*}{2009} & Valor & 1458.45 & 290.20 & 369.64 & - & 2118.29 & 4470.694 \\
\hline & $\%$ & $32.62 \%$ & $6.49 \%$ & $8.27 \%$ & - & $47.38 \%$ & \\
\hline
\end{tabular}


Apuntes CENES Volumen 37, Número 65

enero - junio 2018. Págs. 247-286

Continuación de la Tabla 3.

\begin{tabular}{|c|c|c|c|c|c|c|c|}
\hline \multirow{2}{*}{$\mathbf{2 0 1 0}$} & Valor & 2766.13 & 572.01 & 1005.25 & 1302.73 & 5646.12 & 9364.94 \\
\cline { 2 - 8 } & $\%$ & $29.54 \%$ & $6.11 \%$ & $10.73 \%$ & $13.91 \%$ & $60.29 \%$ & \\
\hline \multirow{2}{*}{$\mathbf{2 0 1 1}$} & Valor & 4150.40 & 842.96 & 1734.60 & 2084.71 & 8812.67 & 11300.77 \\
\cline { 2 - 8 } & $\%$ & $36.73 \%$ & $7.46 \%$ & $15.35 \%$ & $18.45 \%$ & $77.98 \%$ & \\
\hline \multirow{2}{*}{$\mathbf{2 0 1 2}$} & Valor & 5163.29 & 1024.70 & 2220.72 & 2936.06 & 11344.8 & 14372.63 \\
\cline { 2 - 8 } & $\%$ & $35.92 \%$ & $7.13 \%$ & $15.45 \%$ & $20.43 \%$ & $78.93 \%$ & \\
\hline \multirow{2}{*}{$\mathbf{2 0 1 3}$} & Valor & 7070.54 & 1328.86 & 3076.53 & 3907.66 & 15383.6 & 19767.58 \\
\cline { 2 - 8 } & $\%$ & $35.77 \%$ & $6.72 \%$ & $15.56 \%$ & $19.77 \%$ & $77.82 \%$ & \\
\hline
\end{tabular}

Fuente: elaboración propia con base en Ministerio de Economía.

\section{Capacidad para mantener y profundizar el APA}

El contexto en el cual se dan la Ley 26539 y el decreto 252/09 fue uno de recrudecimiento de la competencia de los ensambladores locales frente a la importación extranjera. De hecho, en las Memorias de Newsan de 2008 (p. 5) se indica que: "[m]onitores de LCD se discontinuaron durante este año dado que no logramos por esta vía tener éxito contra la enorme fuerza de los dos líderes coreanos".

Ahora bien, el punto que se busca remarcar en este apartado es que la Ley no solo perjudicó a los importadores (agrupados en la Cámara de Informática y Comunicaciones, Cicomra, y la
Cámara de Comercio e Importación de Equipos de Imagen, Fotografía y Electrónica, Cacieife), sino que también contó con una activa oposición de, por lo menos, tres cámaras de empresarios ensambladores del Territorio Continental: la Cámara Argentina de Máquinas de Oficina, Comerciales y Afines (Camoca), la Cámara Argentina de Industrias Electrónicas, Electromecánicas y Luminotécnicas (Cadieel), la Cámara Argentina de Comercio (CAC) y la Cámara de la Industria Fotográfica (Cifa) ${ }^{7}$. Por el contrario, la medida contó, obviamente, con el apoyo de la entidad que agrupa a las empresas que producen en Tierra del Fuego, la Asociación de Fábricas Terminales Eléctricas (Afarte).

\footnotetext{
${ }^{7}$ Gustavo Vilches, presidente de Sicsa (que fabrica computadoras fuera de Tierra del Fuego) y director de Camoca, afirmaba que "vamos a dejar de existir, acá legislan para beneficiar a Tierra del Fuego [...] Con esta medida, los únicos que se favorecen son empresas como BGH, Frávega o Newsan, que ya están radicadas en Tierra del Fuego" (Sainz, 2009a). Según Camoca, "[el proyecto] solo beneficia a un conjunto de empresarios ubicados en Tierra del fuego, en detrimento de las más de 400 empresas que hay en el país" (La Nación, 2009).
} 
Un punto particularmente conflictivo se dio en torno a las notebooks y netbooks, bienes que en aquel entonces no se producían en Tierra del Fuego y que se veían afectados por el alza de impuestos en el proyecto original, lo cual perjudicaba a los empresarios del territorio continental. Vale la pena, creemos, citar in extenso la visión de Camoca sobre este tema particular,

Debido a los reclamos de la Provincia más rica del País, con el mayor IPC realizados por la Sra. Gobernadora para cubrir la ineficiencia administrativa y con el apoyo incondicional de AFARTE para engrosar los ingresos de 4 o 5 empresas oligopólicas hizo que se creara un conflicto de gran proporción por la posibilidad de despidos masivos en el Sector Industrial del Continente. Luego de una lucha desproporcionada entre las PyMES de CAMOCA y el poder de AFARTE junto a intereses y presiones de la Provincia y la Sra. Ministra de producción, logramos excluir de la Ley del "Impuestazo Tecnológico" a las computadoras portátiles. (Camoca, 2009, p.3)

Pese a que los impuestos internos no se subieron para notebooks y netbooks, al poco tiempo, en julio de 2010, el Gobierno autorizó la producción de estos productos en Tierra del Fuego. El principal mecanismo compensatorio para con las empresas del territorio continental —que fue lo que llevó al presidente de Afarte en ese entonces, Alejandro Mayoral, a afirmar que se habían "limado asperezas" (El Cronista, 2010) - fue el lanzamiento del plan nacional para abastecer de netbooks producidas localmente a las escuelas $^{8}$, lo cual beneficiaba a ambos tipo de productores.

Por último, un factor que salió a la luz en medio de la disputa por la Ley 26 539 y el Decreto 252/09 se refería a las graves dificultades por las que atravesaban empresas con proyectos aprobados para instalarse en la isla. Según Adrián Lamandía, gerente general de Novatech,

Hoy la provincia tiene problemas gravísimos a nivel logístico. Imaginemos cómo será para las empresas nuevas. Para una compañía, trasladarse ahí es directamente imposible. No hay energía, predios o mano de obra calificada [...] Una prueba de esta imposibilidad se ubica en cómo está distribuida la producción en la actualidad. Hay cinco productores y nada más. ¿Por qué no hay más, cómo en Manaos? Por la falta de infraestructura. Ni siquiera se pueden instalar las compañías con planes aprobados hace años. (Eleisegui, 2009)

El mismo medio indicó en 2012 (Eleisegui, 2012) que de los 48 pedidos de

\footnotetext{
${ }_{8}$ Plan denominado "Conectar Igualdad", el cual consiste en la distribución de netbooks a alumnos y docentes de las escuelas secundarias, de educación especial y de los institutos de formación docente de gestión estatal.
} 
radicación aprobados al finalizar el 2005, apenas 13 se encontraban operando en aquel año, muchos de los cuales pertenecían a empresas que estaban previamente en la isla (Newsan, BGH, Radio Victoria, Iatec, Foxman, entre otras). "Si una empresa hoy quiere instalarse, se le dificulta mucho el poder hacerlo. El marco normativo pareciera estar hecho para las firmas que ya están produciendo en esa provincia", señaló Norberto Capellán, presidente de la Cámara de Informática y Comunicaciones de la República Argentina (Eleisegui, 2012).

Hasta aquí se han delineado las principales características que definen al APA asociado a la producción o comercialización de electrónica de consumo vigente a partir de la recuperación económica en Argentina desde 2003. A diferencia de otros APA que existieron en décadas anteriores, especialmente en las década del 70 y el 80, cuando el Estado actuaba como demandante final tanto en momentos de crecimiento económico como de caída, el APA que analizamos no es independiente del ciclo económico, sino que supone como condición de existencia la demanda de consumidores finales locales.

Esto es así debido a la naturaleza del beneficio económico implícito en el régimen, el cual se basa principalmente en devoluciones de IVA y ganancias y no en compras por parte del Estado. Esto último ha aparecido recién con el plan "Conectar Igualdad", pero se concentra solo en un tipo de producto, netbooks. La salida exportadora tampoco es una alternativa para estos grupos, pues no son competitivos internacionalmente. En efecto, la Ley 26 539 y el Decreto 252/09 se dieron en el marco de un recrudecimiento de la competencia externa que amenazaba ciertas líneas de producción.

Esta legislación reafirmó la importancia que este APA tiene para el Estado nacional, en cuanto no solo implicó más beneficios para las empresas que operan bajo el amparo del APA, sino que también perjudicó a las empresas que no eran parte del mismo y que difícilmente podían relocalizar sus plantas productivas de forma tal de hacerse con sus beneficios.

En el próximo apartado se mostrará, finalmente, cómo ha sido la trayectoria reciente de algunos de los grupos que operan bajo este APA, y se pondrá de manifiesto no solo cómo evolucionaron estos grupos en términos productivos y financieros, sino, principalmente, hasta qué punto el APA es determinante para su rentabilidad o, incluso, para su propia existencia.

\section{ESTRATEGIAS DE LOS GRU- POS LOCALES FRENTE AL APA}

Los incentivos de oferta y demanda hasta aquí descritos, afectan, por así 
decirlo, en forma transversal a las empresas que operan en el sector. No obstante, los estudios de casos puntuales no abarcarán este universo, sino un conjunto más acotado: aquellos grupos de capitales locales que avanzaron varios lugares dentro del ranking de empresas de mayor facturación.

Siguiendo la definición de grupo económico que dimos al comienzo del artículo, solo consideraremos aquellas firmas de capitales locales que, más allá de operar en el segmento de fabricación o comercialización de electrónica de consumo, tengan un grado mínimo de diversificación a otras actividades. Es por ello que dejaremos de lado a Brightstar (por ser extranjera), Radio Victoria Fueguina (por no tener estructura de grupo) y BGH (por ser un grupo de larga data que opera en el sector). Consideraremos, por el contrario, a Newsan, Mirgor-Caputo, Garbarino, Frávega y Megatone. La Tabla 5 muestra la evolución de estos grupos, mientras que en las tablas $6 \mathrm{y}$ 7 podemos apreciar su estructura. Para el análisis agruparemos, por un lado, aquellos grupos dedicados exclusivamente a la producción de electrónica de consumo (NewSan y Mirgor) y, por el otro, aquellos dedicados tanto a la producción como a la venta final de estos productos (Garbarino, Frávega y Megatone)

Tabla 4. Puesto de los grupos dentro del ranking de facturación de empresas que operan en Argentina, 2003-2012

\begin{tabular}{|l|c|c|c|c|c|}
\hline Año & NewSan & Mirgor-Caputo & Garbarino & Frávega & Megatone \\
\hline $\mathbf{2 0 0 3}$ & 453 & 452 & 183 & 222 & \\
\hline $\mathbf{2 0 0 4}$ & 511 & 325 & 159 & 127 & \\
\hline $\mathbf{2 0 0 5}$ & 184 & 281 & 99 & 97 & \\
\hline $\mathbf{2 0 0 6}$ & 123 & 139 & 48 & 47 & 97 \\
\hline $\mathbf{2 0 0 7}$ & 125 & 145 & 60 & 56 & 72 \\
\hline $\mathbf{2 0 0 8}$ & 139 & 143 & 68 & 61 & 79 \\
\hline $\mathbf{2 0 0 9}$ & 170 & 189 & 57 & 60 & 101 \\
\hline $\mathbf{2 0 1 0}$ & 109 & 129 & 44 & 68 & 102 \\
\hline $\mathbf{2 0 1 1}$ & 73 & 80 & 53 & 70 & 82 \\
\hline $\mathbf{2 0 1 2}$ & 76 & 86 & 56 & 63 & 77 \\
\hline
\end{tabular}

Fuente: elaboración propia con base en Revista Mercado (2003-2012) 
Tabla 5. Estructura grupos NewSan, Garbarino, Frávega y Megatone

\begin{tabular}{|c|c|c|}
\hline Grupo & Empresas relacionada & $\begin{array}{l}\text { Actividad } \\
\text { principal }\end{array}$ \\
\hline \multirow{7}{*}{ NewSan } & NewSan S.A. & 1 \\
\hline & Noblex Argentina & 1 \\
\hline & Kirbo S.A. & 2 \\
\hline & Pilisar S.A & 1 \\
\hline & Electronic System S.A. & 1 \\
\hline & Misur S.A. & 2 \\
\hline & Call Stock S.A. & 3 \\
\hline \multirow{5}{*}{ Garbarino } & Garbarino S.A.C.I.e I. & 3 \\
\hline & Compumundo S.A & 3 \\
\hline & Digital Fueguina S.A & 1 \\
\hline & Tecnosur S.A. & 1 \\
\hline & Garbarino viajes & 4 \\
\hline \multirow{12}{*}{ Frávega } & Frávega S.A.C.I.e I. & 3 \\
\hline & Banco Saénz S.A. & 2 \\
\hline & Electrofueguina S.A & 1 \\
\hline & Electrodistribuidora S.A & 1 \\
\hline & Ele Erre S.A & 5 \\
\hline & Lorfin S.A & 2 \\
\hline & Almandino S.A & 5 \\
\hline & Sicania & 5 \\
\hline & Consubond y Consubono & 2 \\
\hline & Frali S.A & 6 \\
\hline & Dessay S.A & 2 \\
\hline & Caserta S.A & 2 \\
\hline
\end{tabular}


Continuación de la Tabla 5

\begin{tabular}{|l|l|c|}
\hline \multirow{4}{*}{ Megatone } & Establecimiento Iguazú S.C.A & 3 \\
\cline { 2 - 3 } & Red Megatone S.A. & 5 \\
\cline { 2 - 3 } & Impez S.A. & 7 \\
\cline { 2 - 3 } & Electrónica Glaciar S.A. & 1 \\
\cline { 2 - 3 } & Confina SRL & 2 \\
\cline { 2 - 3 } & Confinas Santa Fe S.A. & 3 \\
\cline { 2 - 3 } & Conmega A.C.E & 7 \\
\cline { 2 - 3 } & Establecimientos La Micaela S.A. & 8 \\
\cline { 2 - 3 } & La Red A.C.E & 7 \\
\cline { 2 - 3 } & Carsa & 3 \\
\cline { 2 - 3 } & Bazar Avenida & 3 \\
\hline
\end{tabular}

1. Fabricación de electrodomésticos y línea blanca, 2. Actividades financieras, 3. Venta al por menor y por mayor, 4. Servicios de turismo, 5. Servicios inmobiliarios, 6. Construcción, 7. Otros servicios, 8. Actividades agropecuarias

Fuente: elaboración propia con base en balances de las empresas.

Tabla 6. Estructura Grupo Caputo

\begin{tabular}{|l|l|c|}
\hline \multicolumn{1}{|c|}{ Segmento } & \multicolumn{1}{|c|}{ Empresa } & Participación \\
\hline \multirow{4}{*}{$\begin{array}{c}\text { Segmento } \\
\text { construcción }\end{array}$} & Caputo S.A.I.C.yF & $87 \%$ \\
\cline { 2 - 3 } & S.E.S. S. A. & $50 \%^{\mathrm{a}}$ \\
\cline { 2 - 3 } & Riverside House S.A. & $25 \%^{\mathrm{a}}$ \\
\cline { 2 - 3 } & Desarrollos Caballito S.A. & $25 \%^{\mathrm{a}}$ \\
\cline { 2 - 3 } & Urbanizadora del Sur S.A. & $35 \%^{\mathrm{a}}$ \\
\cline { 2 - 3 } & Fideicomiso Nuevo Quilmes & $35 \%^{\mathrm{a}}$ \\
\cline { 2 - 3 } & Asociación Civil Nuevo Quilmes S.A. & $35 \%^{\mathrm{a}}$ \\
\cline { 2 - 3 } & Limp Ar Rosario S.A. & $40 \%^{\mathrm{a}}$ \\
\cline { 2 - 3 } & Altos del Puerto S.A. & $32 \%^{\mathrm{a}}$ \\
\cline { 2 - 3 } & Sucursal Chile & $100 \%{ }^{\mathrm{a}}$ \\
\cline { 2 - 3 } & Sucursal Uruguay & $100 \%{ }^{\mathrm{a}}$ \\
\cline { 2 - 3 } & Sucursal Paraguay & $100 \%{ }^{\mathrm{a}}$ \\
\hline
\end{tabular}


Continuación de la Tabla 6

\begin{tabular}{|c|c|c|}
\hline \multirow{4}{*}{$\begin{array}{c}\text { Segmento electrónica y } \\
\text { autopartes }\end{array}$} & Mirgor S.A.C.I.F.I.A. & $52 \%$ \\
\hline & Interclima S.A. (ICSA) & $99,9667 \%^{\mathrm{b}}$ \\
\hline & Capdo S.A. (CAPDO) & $100 \%$ b \\
\hline & latec S.A. & $100 \%$ b \\
\hline \multirow{5}{*}{$\begin{array}{l}\text { Segmento energía (a tra- } \\
\text { vés del grupo Sadesa*) }\end{array}$} & Central Puerto S.A. & $\begin{array}{l}\text { Participación } \\
\text { mayoritaria }^{c}\end{array}$ \\
\hline & Centrales Térmicas Mendoza S.A. & $\begin{array}{l}\text { Participación } \\
\text { mayoritariac }^{c}\end{array}$ \\
\hline & Hidroeléctrica Piedra del Águila S.A. & $\begin{array}{c}\text { Participación } \\
\text { mayoritariac }^{c}\end{array}$ \\
\hline & La Plata Generacion S.A. & $\begin{array}{l}\text { Participación } \\
\text { mayoritariac }\end{array}$ \\
\hline & Distrilec S.A. (contralante de Edesur) & $\begin{array}{c}\text { Participación } \\
\text { minoritariac }^{c}\end{array}$ \\
\hline
\end{tabular}

* La participación del Grupo Caputo en Sadesa es minoritaria, en algunas páginas web se la evalúa como del $23 \%$.

a Los porcentajes se refieren a Caputo S.A.I.C.y F.

b Los porcentajes se refieren a Mirgor S.A.C.I.F.I.A.

c Los porcentajes se refieren a Grupo Sadesa.

Fuente: elaboración propia con base en estados contables de Caputo S.A., Mirgor S.A.C.I.F.I.A., página web de Grupo Sadesa y página web Bolsar.

Grupos dedicados a la producción de electrónica de consumo: Migor-Caputo y NewSan

Como puede verse en la Tabla 6, Mirgor S.A.C.I.F.I.A. y las empresas vinculadas al segmento de electrónica y autopartes forman parte de una estructura mayor, en la cual aparecen otros dos grandes segmentos: construcción y energía. No obstante, en términos de facturación, el segmento aquí analizado es el más importante actualmente ${ }^{9}$.

${ }_{9}^{9}$ Caputo S.A.I.C.yF, pese a su crecimiento y a estar vinculada a un sector de gran dinamismo como la construcción y obra pública, no ha superado el puesto 600 . En el sector energético encontramos empresas de mayor facturación. No obstante, la participación del grupo en este sector es mediada a través de su participación minoritaria en SADESA, a lo cual debe sumarse que este sector fue uno de bajo dinamismo a lo largo de la década del 2000. 
Mirgor S.A.C.I.F.I.A. fue fundada en 1983 para la fabricación de intercambiadores de calor para automóviles. En aquel entonces su producción estaba dividida entre la destinada a automóviles en los cuales el sistema de climatización ya estaba incorporado en la unidad ("equipos con aire") y la destinada a aquellos en los cuales el sistema de climatización se incorporaba como "accesorio" al automóvil ya terminado ("equipos sin aire").

A partir de la información disponible en sus memorias, sintetizada en la Tabla 7 , puede observarse que Mirgor S.A.C.I.F.I.A., a lo largo de la última década, fue diversificando su producción hacia bienes no relacionados con el original. En el año 2002 incorpora los tableros de instrumentos para la marca Volkswagen, mientras que en el 2003 hace lo propio con los enfriadores de aire para tubo. Por su parte, hasta estos años las ventas de la empresa estaban atadas íntegramente al ciclo de la industria automotriz. Vale aclarar, no obstante, que la empresa pudo exportar parte de su producción, aunque, como se deduce del comportamiento de las ventas, esto parece haber sido una política de carácter anticíclico, ya que a medida que se fue recuperando el mercado interno, las exportaciones fueron disminuyendo hasta jugar un papel ínfimo en 2009 y desaparecer en 2010. En este proceso también influyó la devaluación del peso en 2002, la cual implicó una fuerte disminución de costos.

Tabla 7. Venta de Mirgor S.A.C.I.F.I.A, 2001-2013.

Valores en miles de unidades.

\begin{tabular}{|c|c|c|c|c|c|c|c|c|c|c|c|c|c|}
\hline Producto & 2001 & 2002 & 2003 & 2004 & 2005 & 2006 & 2007 & 2008 & 2009 & 2010 & 2011 & 2012 & 2018 \\
\hline $\begin{array}{l}\text { Equipos } \\
\text { con aire }\end{array}$ & 47 & 36 & 41 & 75 & 91 & 173 & 242 & 274 & 234 & 338 & 350 & 300 & 271 \\
\hline $\begin{array}{l}\text { Equipos } \\
\text { sin aire }\end{array}$ & 26 & 19 & 25 & 36 & 33 & 33 & 32 & 39 & 22 & 43 & 41 & 15 & 9 \\
\hline Tableros & & 13 & 18 & 22 & 22 & 14 & 12 & 8 & & & & & \\
\hline $\begin{array}{l}\text { Aire } \\
\text { acondi- } \\
\text { cionado } \\
\text { residen- } \\
\text { cial }\end{array}$ & & & & 17 & 61 & 179 & 247 & 298 & 169 & 216 & 306 & 106 & 96 \\
\hline $\begin{array}{l}\text { Microon- } \\
\text { das }\end{array}$ & & & & & & & & & & 43 & 123 & 96 & 76 \\
\hline
\end{tabular}


Continuación de la Tabla 7

\begin{tabular}{|l|c|c|c|c|c|c|c|c|c|c|c|c|c|}
\hline Celulares & & & & & & & & & & 732 & 2383 & 3959 & 3971 \\
\hline Media-TV & & & & & & & & & & & 12 & 173 & 208 \\
\hline Notebook & & & & & & & & & & & & & 36 \\
\hline Locales & 73 & 68 & 84 & 151 & 207 & 400 & 532 & 619 & 425 & 1372 & 3204 & 4649 & 4667 \\
\hline $\begin{array}{l}\text { Exporta- } \\
\text { ción }\end{array}$ & 50 & 70 & 102 & 82 & 49 & 62 & 31 & 57 & 5 & & & & \\
\hline $\begin{array}{l}\text { Ventas } \\
\text { Totales }\end{array}$ & $\mathbf{1 2 3}$ & $\mathbf{1 3 7}$ & $\mathbf{1 8 7}$ & $\mathbf{2 3 2}$ & $\mathbf{2 5 6}$ & $\mathbf{4 6 2}$ & $\mathbf{5 6 3}$ & $\mathbf{6 7 6}$ & $\mathbf{4 3 0}$ & $\mathbf{1 3 7 2}$ & $\mathbf{3 2 0 4}$ & $\mathbf{4 6 4 9}$ & $\mathbf{4 6 6 7}$ \\
\hline
\end{tabular}

Fuente: elaboración propia con base en Memorias de Mirgor S.A.C.I.F.I.A. (2001-2013)

No obstante, la diversificación que resultará fundamental para la empresa es aquella relacionada con la electrónica de consumo doméstico, que comienza en el año 2004 con la expansión en torno a la refrigeración doméstica ${ }^{10}$. En este caso, el grupo avanzó hacia un producto fuertemente relacionado con su producción principal. Siguiendo esta misma lógica de diversificación hacia la electrónica de consumo, a fines del 2008 el grupo adquirió la firma "Industria Austral de Tecnología S.A." (Iatec S.A.), empresa alcanzada con beneficio de la promoción industrial de Tierra del Fuego para la producción de distintos productos electrónicos, tales como televisores, hornos microonda, celulares, equipos de sonido, entre otros.
Un hecho destacado dentro de la diversificación en la producción que lleva adelante el grupo es que el peso de la nueva cartera de bienes eléctricos incorporados con Iatec comenzó a desplazar no ya a la climatización automotriz sino, incluso, a la residencial. Por su parte, dentro de la electrónica de consumo, el producto de mayor dinamismo estuvo representado en los celulares, a partir del acuerdo que el grupo llevó a cabo con Nokia en 2010 para la confección de equipos de media y alta gama. En las memorias de la empresa de aquel año, el grupo relaciona el acuerdo con Nokia con la mencionada Ley 26 539. Esta misma ley permitió al grupo, en el año siguiente, firmar acuerdos con LG y Whirlpool para la producción de microondas.

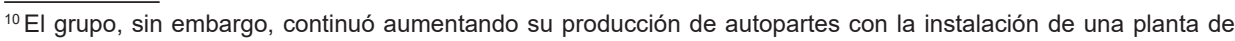
armado y provisión "justo a tiempo" de ruedas en el predio de General Motors en 2006. En ese mismo año el grupo adquirió una participación controlante en Capdo S.A., sociedad que poseía un inmueble en la provincia de Buenos Aires, el cual permitió ampliar y mejorar la provisión de bienes.
} 
Por su parte, la Tabla 8 da cuenta del completamente de estos beneficios impacto de los beneficios recibidos para operar con ganancias, por cuanto bajo el amparo del Régimen de Pro- los beneficios asociados al APA repremoción fueguino sobre los resultados sentan, para todo el período considede Mirgor S.A.C.I.F.I.A ${ }^{11}$. Como se rado, montos que van desde 2.5 a 10 puede observar, la empresa depende veces del total de la ganancia neta.

Tabla 8. Cálculo del peso del beneficio fiscal sobre la ganancia neta, 20012013. Valores en millones de pesos corrientes

\begin{tabular}{|c|c|c|c|c|c|c|c|c|c|c|c|c|c|}
\hline & 2001 & 2002 & 2003 & 2004 & 2005 & 2006 & 2007 & 2008 & 2009 & 2010 & 2011 & 2012 & 2013 \\
\hline 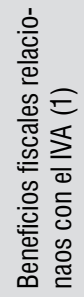 & 14.8 & 15.2 & 14.1 & 29.0 & 43.4 & 91.2 & 133.2 & 178.8 & 140.9 & 300.1 & 608.1 & 707.5 & 860.0 \\
\hline 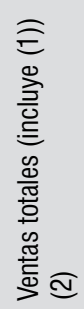 & 99.2 & 122 & 114.7 & 201.6 & 288.9 & 566.3 & 819.7 & 1061.7 & 831.8 & 1704 & 3373.5 & 4044.9 & 4883.7 \\
\hline 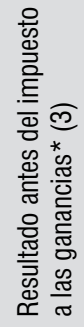 & & -14.8 & -2.1 & 8.6 & 20.2 & 40.0 & 60.1 & 28.3 & -9.3 & 28.7 & 80.6 & 152.4 & 234.8 \\
\hline
\end{tabular}

\footnotetext{
${ }^{11}$ Que, vale la pena aclarar, no incluyen todos los beneficios (los derechos aduaneros no están computados, por ejemplo).
} 
Continuación de la Tabla 8

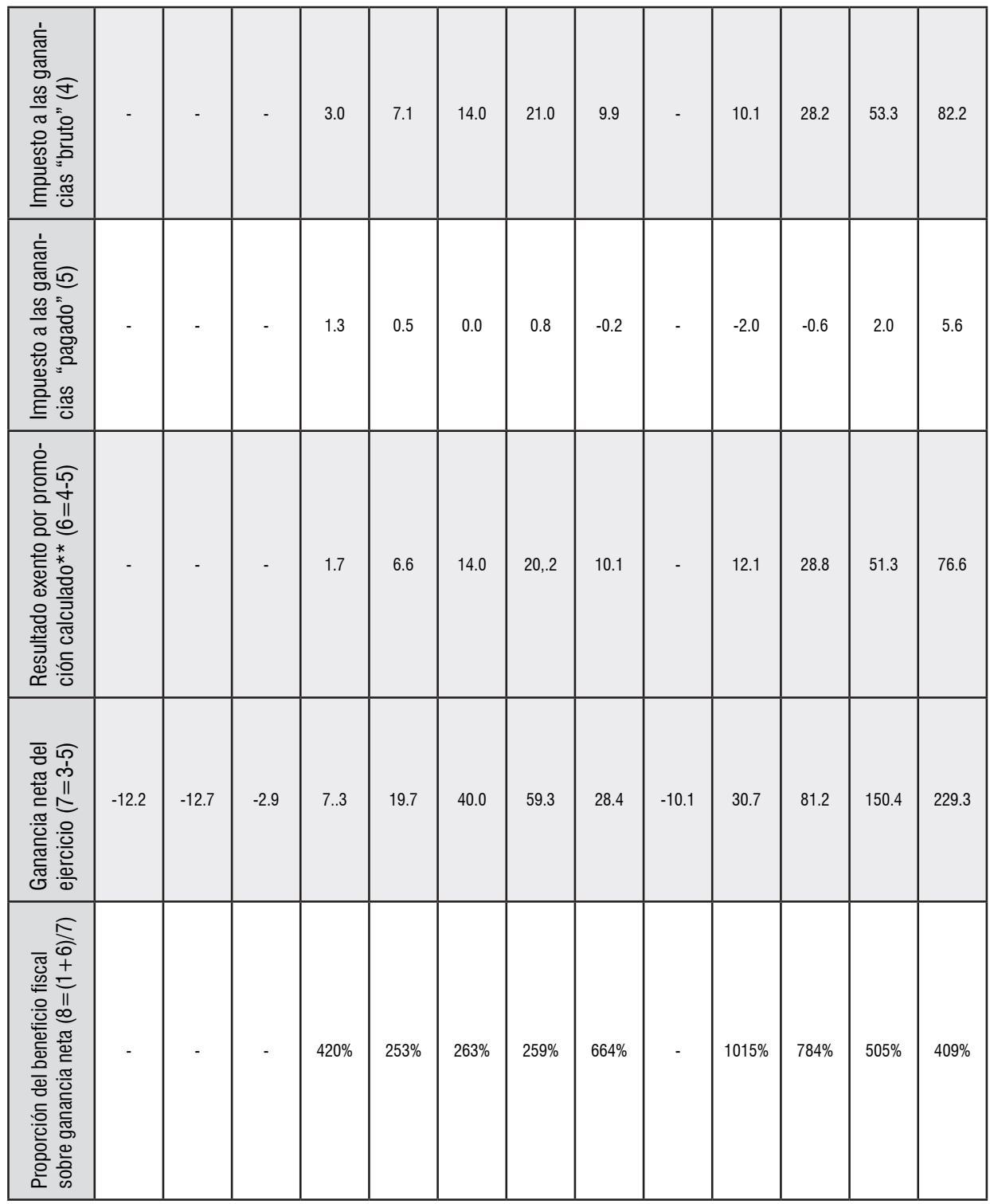

* frente a resultados negativos, la ley misma lo contempla como un crédito fiscal futuro.

** En los casos en que la ganancia es mayor luego de "pagado" el impuesto a las ganancias, se debe a que la empresa hace uso del crédito fiscal por quebranto impositivo de otros períodos.

Fuente: elaboración propia con base en estados contables de Mirgor S.A.C.I.F.I.A. (2001-2013) 
En el caso de NewSan, a diferencia de Mirgor, desde sus orígenes se dedicó a la producción de artículos electrodomésticos. El grupo nació en 1991 tras la fusión de la firma local Sansei con Sanelco, licenciataria para la Argentina de la marca Sanyo, perteneciente a la japonesa Sanyo Electric Co. Esta última contaba con dos plantas en Tierra del Fuego instaladas en 1980 y 1982, mientras que Sansei contaba con la propia desde 1987. En 1999 adquirió la empresa Noblex Argentina S.A., que incluía tanto a Noblex como ATMA, las cuales se transformarán luego en sus nuevas marcas propias, en tanto Sanyo, en todo el mundo, había abandonado para ese entonces la venta de artículos para el hogar para dedicarse a la fabricación de chips para uso informático. Con esa incorporación, el grupo, además de nuevas marcas y capacidad productiva, aumentó su presencia en el interior del país.

En 2004 comenzó su diversificación en sectores no pertenecientes a la electrónica de consumo y electrodomésticos. En principio hacia la construcción para segmentos de alto poder adquisitivo, con un complejo de viviendas de lujo y una torre de viviendas en la Capital Federal, y barrios cerrados en distintos puntos de la provincia de Buenos Aires en 2005 y 2006. El grupo también se diversificó en 2011, a través de Newsan Food, hacia los alimentos, más precisamente a la exportación de productos de la industria pesquera, miel, vino, mosto, ciruelas y pasas de uva. A estos productos se le agregarán luego el alimento balanceado pelleteado para peces, aceite de oliva, harina de soja, arroz y garbanzos. En el caso de la industria pesquera, su principal negocio de exportación, el grupo fue el principal exportador de pesca del país en 2014. La decisión de abrir esta nueva unidad de negocios, vale la pena aclarar, se debió más a una "recomendación" del Gobierno que a una voluntad genuina del grupo. Como lo afirma el presidente y director general de Newsan, Luis Gali:

La Secretaría de Comercio [...] nos abrió los ojos. Nos transmitió un problema del país en relación a la falta de divisas, pero era un problema de nuestra empresa. Hoy sentimos que lo mejor que nos pasó es querer tener balanceada y diversificada nuestra actividad. (Moreno, 2014)

No obstante, es a través de la electrónica de consumo que se explica el gran crecimiento del grupo a lo largo de la década. Como puede observarse en la Tabla 9, la empresa incorporó gran cantidad de productos dentro de la electrónica de consumo. Lo mismo sucedió con marcas internacionales, tales como Pioneer en 2004; LG, JVC, Braun y Nintendo en 2008; Alcatel, Kodak, Vaio y Lenovo en 2010 y Motorola, Huawei y Compaq en 
2014. Asimismo, se inauguraron nuevas plantas en Tierra del Fuego como la Planta 5 (ex Aurora-Grundig) destinada a la producción de LCD y monitores en 2011. Por fuera de la provincia austral, el grupo abrió fábricas en la provincia de Buenos Aires en 2012 (destinada a la producción de pequeños electrodomésticos) y 2014 (destinada a la producción de línea blanca como freezers, heladeras, lavarropas y lavavajillas).

Tabla 9. Producción del grupo NewSan, 2008-2011.

Valores en miles de unidades.

\begin{tabular}{|l|c|c|c|c|}
\hline & 2008 & 2009 & 2010 & 2011 \\
\hline Televisores & 418661 & 246663 & 339635 & 191100 \\
\hline Televisores LCD y plasma & 73759 & 153338 & 385470 & 679615 \\
\hline Aire acondicionado & 297272 & 90340 & 289285 & 470589 \\
\hline Hornos microondas & 117071 & 95669 & 114188 & 185396 \\
\hline Dvd & - & 104369 & 157629 & 4238 \\
\hline Audio & - & 7019 & 8971 & 28673 \\
\hline Cámara de fotos y camcorders & - & - & 109262 & 278436 \\
\hline Celulares & - & - & 196842 & 454125 \\
\hline Monitores & - & - & 189690 & 456041 \\
\hline Netbooks & - & - & - & 211573 \\
\hline Decodificadores & - & - & - & 78155 \\
\hline
\end{tabular}

Fuente: elaboración propia con base en Memorias de NewSan (2008-2011)

En el caso de este grupo, como en el anterior, es interesante estudiar el peso que tiene el beneficio promocional dentro del rubro de electrónica de consumo (Tabla 10). Como puede verse, al igual que en el caso de Mirgor, la suma de las devoluciones de IVA y ganancias supera ampliamente las ganancias netas del grupo. En el caso puntual de este grupo, también ha sido beneficiado con el "Programa de Financiamiento Productivo del Bicentenario" a tasa fija del 9,9\% (mucho menor que la inflación del período) por un monto de $\$ 100970$ 000, como también por el programa "Conectar Igualdad" en 2011, por el cual fue seleccionado para fabricar 212500 netbooks. 
Tabla 10. Cálculo del peso del beneficio fiscal sobre la ganancia neta, 20072013 Valores en miles de pesos corrientes

\begin{tabular}{|c|c|c|c|c|c|c|c|}
\hline & 2007 & 2008 & 2009 & 2010 & 2011 & 2012 & 2013 \\
\hline $\begin{array}{l}\text { Beneficios fiscales } \\
\text { relacionaos con el } \\
\text { IVA (1) }\end{array}$ & 125236 & 134448 & 135813 & 306556 & 518769 & 698153 & 972664 \\
\hline $\begin{array}{l}\text { Ventas totales } \\
\text { (incluye (1)) (2) }\end{array}$ & 965723 & 996699 & 945445 & $\begin{array}{c}1989 \\
643\end{array}$ & $\begin{array}{c}3714 \\
227\end{array}$ & $\begin{array}{c}4580 \\
215\end{array}$ & $\begin{array}{c}6642 \\
866\end{array}$ \\
\hline $\begin{array}{l}\text { Resultado antes del } \\
\text { impuesto a las } \\
\text { ganancias* }(3)\end{array}$ & 83653 & 48123 & 83387 & 212587 & 279049 & 328196 & 592998 \\
\hline $\begin{array}{l}\text { Impuesto a las } \\
\text { ganancias "bruto" } \\
\text { (4) }\end{array}$ & 29279 & 16843 & 29186 & 74405 & 97667 & 114869 & 207549 \\
\hline $\begin{array}{c}\text { Impuesto a las } \\
\text { ganancias "pagado" } \\
\text { (5) }\end{array}$ & 7494 & 858 & 8080 & 11186 & 32754 & 18182 & 4040 \\
\hline $\begin{array}{l}\text { Resultado exento por } \\
\text { promoción } \\
\text { calculado** }(6=4-5)\end{array}$ & 21784 & 15985 & 21106 & 63219 & 64913 & 96686 & 203509 \\
\hline $\begin{array}{l}\text { Ganancia neta del } \\
\text { ejercicio }(7=3-5)^{*}\end{array}$ & 75674 & 47021 & 74722 & 201701 & 243172 & 298909 & 585248 \\
\hline $\begin{array}{l}\text { Proporción del } \\
\text { beneficio fiscal } \\
\text { sobre ganancia neta } \\
(8=(1+6) / 7)\end{array}$ & $194 \%$ & $320 \%$ & $210 \%$ & $183 \%$ & $240 \%$ & $266 \%$ & $201 \%$ \\
\hline
\end{tabular}

* La diferencia en el cálculo se explica por los conceptos de "Variación previsión para desvalorización de impuesto diferido" y "Diversos".

Fuente: elaboración propia con base en estados contables de NewSan (2007-2013) 
Grupos dedicados a la producción y comercialización a consumidores finales de electrónica de consumo: Garbarino, Frávega y Megatone

Garbarino fue fundado en 1951 como un emprendimiento dedicado originalmente a la venta de discos de pasta en la Capital Federal. No obstante, su principal negocio pasó a ser la venta de electrodomésticos, teniendo una fuerte expansión de sucursales en la década de los 90 y también en el período de 2001-2005, en el cual abrió 22 puestos de venta. A partir del 2005, la empresa invirtió en la instalación de su propia fábrica destinada a la producción de electrodomésticos, hecho que se señala como "un hito fundamental en la estrategia de la empresa para optimizar sus condiciones de abastecimiento y costo de adquisición de los productos a comercializar" (Garbarino, 2009, p.2). La primera etapa de este proyecto fabril culminó en 2007 y al año siguiente comenzó la comercia- lización de sus productos compuestos, originalmente, por microondas y aires acondicionados. En el año 2010 inició, asimismo, la producción y comercialización de televisores. Por último, el grupo creó en el año 2009 la empresa Garbarino Viajes. La decisión, en este caso, se debió a un cambio de tendencia dentro de las modalidades de venta de electrodomésticos, como lo es la venta mediante lista de casamiento.

Pese a que la información disponible para esta empresa es mucho menor que la de las anteriores, los valores de los estados contables disponibles en la Tabla 11 permiten dar cuenta del hecho de que si bien los beneficios promocionales obtenidos a partir de la ensambladora de la empresa tienen un peso importante dentro de su ganancia neta, no resultan mayores al $100 \%$, como en el caso de los grupos que solo producen bienes electrónicos. Esto es consistente con el hecho de que la empresa ya operaba antes de integrarse verticalmente, a la vez que es la vendedora final de esos productos.

Tabla 11. Cálculo del peso del beneficio fiscal sobre la ganancia neta, 20082010. Miles de pesos corrientes

\begin{tabular}{|l|c|c|c|}
\hline & 2008 & 2009 & 2010 \\
\hline Beneficios fiscales relacionaos con el IVA (1) & 6775 & 18340 & 111691 \\
\hline Ventas totales (incluye (1)) (2) & 58115 & 140536 & 727557 \\
\hline Resultado antes del impuesto a las ganancias* (3) & 9969 & 13997 & 151763 \\
\hline
\end{tabular}


Continuación de la Tabla 11

\begin{tabular}{|l|c|c|c|}
\hline Impuesto a las ganancias “bruto” (4) & 3489 & 4899 & 53117 \\
\hline Impuesto a las ganancias “pagado” (5) & 1525 & 604 & 1087 \\
\hline Resultado exento por promoción calculado** (6=4-5) & 1964 & 4295 & 52030 \\
\hline Ganancia neta del ejercicio (7=3-5)* & 40502 & 112115 & 257290 \\
\hline $\begin{array}{l}\text { Proporción del beneficio fiscal sobre ganancia neta } \\
(\mathbf{8}=(\mathbf{1 + 6}) / \mathbf{7}\end{array}$ & $21.58 \%$ & $20.19 \%$ & $63.63 \%$ \\
\hline
\end{tabular}

Fuente: elaboración propia con base en estados contables de Garbarino (2008-2010)

En el caso de Frávega, al igual que Garbarino, su actividad principal es el negocio del retail. La empresa, no obstante, es más antigua que Garbarino, ya que inició sus actividades en 1910. Asimismo, el grupo presenta una estructura mucho más diversificada que la de su par, porque posee, desde 1976, el Banco Sáenz S.A., un banco privado dirigido a la atención de personas y pequeñas y medianas empresas. Actualmente, el banco concentra su actividad en el otorgamiento de préstamos personales para la compra de electrodomésticos y artículos de Frávega, captando sus clientes a través de puestos de venta situados en los locales de la cadena. La firma Lorfin, también perteneciente al grupo, se dedica a administrar estos préstamos personales.

También desembarcó en 1999, a través de la empresa Frali, en el sector de la construcción, con un barrio cerrado en la provincia de Buenos Aires. En 2004 inició la construcción de un barrio cerrado de lujo con una laguna artificial, canchas de golf y un hotel 5 estrellas. En 2007 comenzó la construcción de otro hotel 5 estrellas, mientras que en 2008 haría lo propio con la construcción de un barrio cerrado destinado al segmento de mayor poder adquisitivo de la población.

El grupo, por otra parte, incursionó mucho antes que Garbarino en la fabricación de la electrónica de consumo, en tanto su firma Electrofueguina fue instalada a principios de la década del noventa en Tierra del Fuego en sociedad con otras empresas a las que luego les compraría sus respectivas participaciones. El grupo también instaló una fábrica en Capital Federal destinada al armado de computadoras de la marca Admiral en 2004. Si bien no disponemos de información de balances del grupo, dado que no cotiza en bolsa, en la Tabla 12 podemos apreciar el gran incremento de sus ventas en valores constantes a lo largo del período. 
Apuntes CENES Volumen 37, Número 65

enero - junio 2018. Págs. 247-286

Tabla 12. Ventas de Frávega, 2003-2013. Millones de pesos de 2003

\begin{tabular}{|l|c|c|c|c|c|c|c|c|c|c|c|}
\hline Año & 2003 & $\mathbf{2 0 0 4}$ & $\mathbf{2 0 0 5}$ & $\mathbf{2 0 0 6}$ & $\mathbf{2 0 0 7}$ & $\mathbf{2 0 0 8}$ & $\mathbf{2 0 0 9}$ & $\mathbf{2 0 1 0}$ & $\mathbf{2 0 1 1}$ & $\mathbf{2 0 1 2}$ & $\mathbf{2 0 1 3}$ \\
\hline Ventas & 274 & 589 & 807 & 1383 & 1421 & 1264 & 1224 & 1198 & 1244 & 1260 & 1512 \\
\hline
\end{tabular}

Fuente: elaboración propia con base en Revista Mercado.

Por último, la cadena Megatone nace en los 80 a partir de una alianza de Electrónica Megatone, Carsa y Bazar Avenida, de las ciudades de Santa Fe, Resistencia y Rafaela respectivamente. Esta alianza no implicó una fusión de las empresas originales, pues estas mantuvieron su independencia pero comenzaron a operar bajo un nombre común. A diferencia de las dos comercializadoras previamente expuestas, Megatone basó sus negocios en el interior del país. De hecho, su llegada a la Capital Federal se dio recién en 2007 (aunque en el caso del Gran Buenos Aires ya contaba para ese entonces con 18 sucursales).
La mayor presencia dentro de la Capital Federal se dio a partir de la compra de la cadena Musimundo en 2011, 1levada a cabo por dos de las empresas originales, Carsa y Electrónica Megatone. El otro socio, Bazar Avenida, había entrado en concurso de acreedores en 2009 debido a la crisis internacional que llevó a la caída en la demanda de productos de electrónica (la Tabla13 muestra cómo esto afectó las ventas del grupo). Con esta compra, Carsa y Electrónica Megatone transformaron los locales de Musimundo en sucursales de Megatone (aunque usando la marca Musimundo).

Tabla 13. Ventas de Red Megatone, 2006-2013. Millones de pesos de 2003

\begin{tabular}{|l|c|c|c|c|c|c|c|c|}
\hline & $\mathbf{2 0 0 6}$ & $\mathbf{2 0 0 7}$ & $\mathbf{2 0 0 8}$ & $\mathbf{2 0 0 9}$ & $\mathbf{2 0 1 0}$ & $\mathbf{2 0 1 1}$ & $\mathbf{2 0 1 2}$ & $\mathbf{2 0 1 3}$ \\
\hline Ventas & 709 & 1137 & 1001 & 762 & 768 & 964 & 1101 & 1028 \\
\hline
\end{tabular}

Fuente: elaboración propia con base en Revista Mercado.

Al igual que las otras comercializadoras, dispone también de un segmento de préstamos a través de Confina, empresa que surgió en el año 1987 para cubrir el segmento del mercado no alcanzado por la banca tradicional. Asimismo cuenta con una ensambladora en Tierra del Fuego,
Electrónica Glaciar, la cual comenzó sus operaciones en 2005.

\section{CONCLUSIONES}

A lo largo de este artículo se ha mostrado cómo, en un contexto general de extranjerización de parte de las 
empresas de capitales argentinos más importantes, una serie de grupos vinculados a la producción o comercialización (o a ambas actividades) de electrónica de consumo lograron pasar, desde lugares relativamente marginales en el año 2003, al lote de las 100 primeras empresas en el 2014.

Para comprender este fenómeno acudimos el concepto de ámbito privilegiado de acumulación (Castellani, 2009). El carácter privilegiado de este ámbito radica en una serie de puntos, entre los cuales están: (1) el monto de recursos destinado al Régimen de Promoción Económica de la Provincia de Tierra del Fuego que llega a concentrar más de tres cuartas partes del total de los gastos tributarios originados en regímenes de promoción económica, (2) la sanción de nuevas leyes en favor del sector durante la última década, que se sumaron a las ya existentes y perjudicaron a otras fracciones del empresariado, (3) la limitada posibilidad de acceso para nuevas empresas.

Asimismo, este APA, a diferencia de otros vigentes en los 70 y 80 en Argentina, tiene como principal condición de existencia la demanda de consumo de los hogares en un contexto de crecimiento económico y créditos al consumo, por sobre las compras del Estado. No obstante, programas de compra como "Conectar Igualdad" o de financiamiento a tasas de interés real negativa como el "Programa de
Financiamiento Productivo del Bicentenario" también beneficiaron a estos grupos.

El estudio de los grupos seleccionados, a partir del análisis detallado de su balance y memorias, confirmó la importancia del APA. En primer lugar, todos los grupos aquí analizados cuentan con una o más plantas que se benefician del Régimen. A su vez, si bien NewSan, Mirgor y Frávega tenían sus fábricas desde antes del período estudiado, Megatone y Garbarino abrieron fábricas en el sur logrando así integrarse verticalmente a principios de la década del 2000. Vale la pena aclarar que esto fue apenas comenzado el período de recuperación económica y antes de la sanción de la Ley 26539 y del Decreto 252/09, que profundizó el APA y generó conflictos con otros empresarios.

El análisis de los estados contables de los grupos que solo producen electrónica de consumo, Mirgor y NewSan, mostró que los beneficios del APA son fundamentales para que ambos operen con ganancias. En el caso de los grupos que producen y comercializan para los hogares - Garbarino, Frávega y Megatone-, los estados contables de Garbarino (los únicos disponibles) muestran que, si bien los beneficios asociados al APA son una parte importante de sus ganancias, el peso es menor que en el caso de los grupos que solo producen electrónica, lo cual es 
coherente con que Garbarino operaba antes de integrarse verticalmente, a la vez que logra hacerse de los beneficios de la venta final al público.

Las memorias de Mirgor, por su parte, ilustraron cómo el grupo fue adaptando su producción para maximizar los beneficios del APA. Teniendo originalmente los beneficios del Régimen Fueguino en la producción de autopartes, decidió incursionar primero en el segmento de aires acondicionados para el hogar y luego en la producción de celulares, gracias al acuerdo con Nokia, posibilitado, a su vez, por la Ley 26 539 y el Decreto 252/09.

Por último, no hay que dejar de mencionar que los grupos aquí tratados, si bien presentan cierto grado de diversificación en sectores ajenos a la producción de electrónica de consumo, basaron su crecimiento en estos últimos sectores. Prueba de ello es que ninguna de las empresas vinculadas a sectores ajenos al de la electrónica de consumo pertenecientes a los grupos NewSan, Garbarino, Frávega y Megatone figura en el ranking de las 1000 empresas de mayor facturación. El caso de Mirgor-Caputo es distinto ya que encontramos empresas que figuran en el Ranking (no obstante, con una gravitación menor al de la electrónica de consumo).

Debido a esto, podemos decir que, al menos para NewSan, Garbarino, Frávega y Megatone, la diversificación no ha funcionado como un elemento determinante en su crecimiento a lo largo del período considerado, sino, más bien, como una estrategia de diversificación de cartera de carácter seguro (construcción de viviendas y barrios cerrados para los sectores de mayores ingresos) o forzados por su carácter de importadores neto (pesca y otros productos agropecuarios). Esto no hace más que reafirmar el carácter determinante del APA para estos grupos. De hecho, a partir de la asunción del presidente Mauricio Macri en diciembre de 2015, el nuevo Gobierno se ha mostrado reacio a sostener este APA, anunciando para los primeros meses de 2017 reducciones en los aranceles a la importación de productos electrónicos, lo cual ha llevado al cierre de plantas y despido de trabajadores. Con esta medida, el Gobierno pretende, entre otras cuestiones, estimular la competitividad de las empresas locales. Sin embargo, la información recabada en este trabajo lleva a cierto escepticismo en relación con ese objetivo. 


\section{REFERENCIAS}

Aldrighi, D. M. \& Postali, F. A. (2010). Business Groups in Brazil. In $O x$ ford Handbook of Business Groups. https://doi.org/10.1093/oxford$\mathrm{hb} / 9780199552863.003 .0013$

Artopoulos, A. (2006). Caso Tenaris: una corporación global desde el sur. Argentina: Universidad de San Andrés, Departamento de Administración.

Artopoulos, A. (2009). Sociedad del conocimiento en Argentina: el caso de una empresa-red, Tenaris. Redes, 15(29), 241-276.

Azpiazu, D. (1988). La promoción a la inversión industrial en la Argentina: efectos sobre la estrutura industrial, 1974-1987. Naciones Unidas, Comisión Económica para América Latina y el Caribe.

Bisang, R. (1998). Conglomerados económicos en la Argentina: orígenes y evolución reciente. Argentina: UNGS.

Camoca. (2009). Informe de informática. Recuperado de http://www.camoca. com.ar/informe-del-ano-2009/

Castellani, A. (2009). Estado, empresas y empresarios: la construcción de ámbitos privilegiados de acumulación entre 1966 y 1989. Buenos Aires: Prometeo Libros.

Castellani, A. \& Gaggero, A. (2012). La retirada heterogénea. Estrategias y desempeños de los grupos económicos nacionales en la Argentina de los años noventa. Revista Apuntes, Lima, Universidad del Pacifico, 203-238.

Centro de Estudios para la Producción. (2001). El área aduanera especial de Tierra del Fuego y la zona franca de Manaos: objetivos comunes, trayectorias divergentes. En Notas de la economía real. Buenos Aires: Secretaría de Industria, Comercio y Pymes, Ministerio de Economía y Producción de la República Argentina.

Dahse, F. (1979). El mapa de la extrema riqueza: los grupos económicos y el proceso de concentración de capitales. Sevilla, España: Aconcagua.

El Cronista. (2010, 8 de julio). BGH y NewSan fabricarán notebooks en Tierra del Fuego. El Cronista. Recuperado de http://www.cronista.com/impresageneral/BGH-y-NewSan-fabricaran-notebooks-en-Tierra-del-Fuego--20100708-0059.html 
Eleisegui, P. (2009, 7 de octubre). Impuestazo: la verdad que esconde Tierra del Fuego y el "corralito" a las empresas. iProfesional. Recuperado de http:// www.iprofesional.com/notas/88449-Impuestazo-la-verdad-que-esconde-Tierra-del-Fuego-y-el-corralito-a-las-empresas

Eleisegui, P. (2012, febrero 24). El "mito" de la radicación: ¿cuántas empresas pudieron instalar sus fábricas en la "soñada" Tierra del Fuego? iProfesional. Recuperado de http://www.iprofesional.com/notas/127643-El-mito-de-la-radicacin-cuntas-empresas-pudieron-instalar-sus-fbricas-en-lasoada-Tierra-del-Fuego

Filadoro, A. (2007). Impactos del régimen de promoción en la estructura industrial de Tierra del Fuego. La Plata, Argentina: Instituto de Estudios Fiscales y Económicos IEFE.

Fishlow, A. (1972). Origins and Consequences of Import Substitution in Brazil. International Economics and Development: Essays in Honor of Raul Prebisch, 311-365. https://doi.org/10.1016/B978-0-12-216450-7.50029-3

Fracchia, E., Mesquita, L. \& Quiroga, J. (2010). Business Groups in Argentina. Oxford University Press. https://doi.org/10.1093/oxford$\mathrm{hb} / 9780199552863.003 .0012$

Gaggero, A., Schorr, M. \& Wainer, A. (2014). Restricción eterna: el poder económico durante el kirchnerismo. Buenos Aires: Futuro Anterior.

Garbarino. (2008-2010). Memorias y estados contables. Recuperado de http:// www.cnv.gob.ar/info_financiera.asp

Garbarino. (2010). Programa global de valores fiducidarios "Garbarino”. Recuperado de http://www.cnv.gob.ar/info_financiera.asp

García, M. (2005, 7 de agosto). Gracias a la explosión de las ofertas y la vuelta de las cuotas, se está produciendo la revancha de la clase media. La Nación. Recuperado de http://www.lanacion.com.ar/728051-gracias-a-la-explosion-de-las-ofertas-y-la-vuelta-de-las-cuotas-se-esta-produciendo-la-revancha-de-la-clase-media

Garófalo, A. (2004). Régimen especial fiscal y aduanero. Ley 19.640. Antecedentes, configuración y aplicabilidad del subrégimen industrial. Argentina: Cámara Fueguina de la Pequeña y Mediana Industria. 
Garrido, C. \& Peres, W. (1998). Las grandes empresas y grupos industriales latinoamericanos en los años noventa. Grandes empresas y grupos industriales latinoamericanos, (pp. 13-80). México: Siglo XXI.

INDEC. (2015a). Encuesta de centros de compras (centros comerciales). Recuperado de https://www.indec.gov.ar/

INDEC. (2015b). Encuesta de comercios de electrodomésticos y artículos para el hogar. Recuperado de https://www.indec.gov.ar/

INDEC. (2015c). Encuesta de supermercados. Recuperado de https://www.indec.gov.ar/

Jacobs, E. (1981). La evolución reciente de los grupos de capital privado nacional. Economía Mexicana, (3), 23-44.

Jones, G. \& Colpan, A. M. (2010). Business Groups in Historical Perspectives. Oxford Handbook of Business Groups. https://doi.org/10.1093/oxford$\mathrm{hb} / 9780199552863.003 .0003$

Khanna, T. \& Yafeh, Y. (2007). Business Groups in Emerging Markets: Paragons or Parasites? Journal of Economic literature, 45(2), 331-372.

Kosacoff, B., Barbero, M. I., Forteza, J., Porta, F. \& Stengel, A. (2001). Globalizar desde Latinoamérica. El caso Arcor. Buenos Aires: McGraw Hill Interamericana.

La Nación. (2008, noviembre 10). La Anses ya invierte en fideicomisos. La Nación. Recuperado de http://www.lanacion.com.ar/1068332-la-anses-ya-invierte-en-fideicomisos

La Nación. (2009, septiembre 10). Recrudece la disputa entre empresas. La Nación. Recuperado de http://www.lanacion.com.ar/1172726-recrudece-la-disputa-entre-empresas

Lefort, F. (2010). Business Groups in Chile. Oxford Handbook of Business Groups. https://doi.org/10.1093/oxfordhb/9780199552863.003.0014

Manzanal, M. \& Rofman, A. B. (1989). Las economías regionales de la Argentina: crisis y políticas de desarrollo. Buenos Aires: Centro Editor de América Latina. 
Manzanelli, P., \& Schorr, M. (2012). Extranjerización y poder económico industrial en Argentina. Problemas del Desarrollo, 43(170), 39-67.

Martínez, G. V. (2017). Los conglomerados empresariales en el Ecuador: un análisis histórico, económico y político. Apuntes del CENES, 36(63), 247278. https://doi.org/10.19053/01203053.v36.n63.2017.5456

Mirgor S.A.C.I.F.I.A. (2001-2013). Memorias y estados contables. Recuperado de http://www.cnv.gob.ar/info_financiera.asp

Moreno, G. (2014, octubre 3). En busca de equilibrio. Revista Veintitrés. Recuperado de http://www.newsan.com.ar/es/portfolio/en-busca-de-equilibrio-2/

NewSan S.A. (2007-2011). Memorias y estados contables. Recuperado de http:// www.cnv.gob.ar/info_financiera.asp

Nochteff, H. (1984). Desindustrialización y retroceso tecnológico en Argentina, 1976-1982. Buenos Aires: Facultad Latinoamericana de Ciencias Sociales, Grupo Editor Latinoamericano, Emecé Distribuidora.

Passetti, P. (2014). La industria electrónica en la posconvertibilidad. Realidad Económica, (284), 113-132.

Rabinovich, J. (2017). Los nuevos grupos y sus viejas prácticas en la Argentina reciente (2003-2014). Entre ámbitos privilegiados de acumulación, especulación y monopolios. Mimeo.

Rabinovich, J. \& Giliberto, M. (2015). Respuestas y vicisitudes de los Grupos Económicos Nacionales frente a las reformas pro mercado. Anuarios del CEEED, 6(6).

Rafele, E. \& Fernández, P. (2013). Los patrones de la Argentina K. Los negocios, el poder y la política de los verdaderos dueños de la década ganada. Buenos Aires: Planeta.

Revista Mercado. (2003-2012). Las 1000 que más venden.

Sainz, A. (2004, julio 1). Tarjetas: siguen las cuotas sin interés en grandes comercios. La Nación. Recuperado de http:/www.lanacion.com.ar/614670-tarjetas-siguen-las-cuotas-sin-interes-en-grandes-comercios 
Sainz, A. (2005, 7 de agosto). Es un fenómeno similar al de los 90. La Nación. Recuperado de http://www.lanacion.com.ar/728056-es-un-fenomeno-similar-al-de-los-90

Sainz, A. (2009a, 8 de mayo). Más críticas a una suba impositiva. La Nación. Recuperado de http://www.lanacion.com.ar/1125636-mas-criticas-a-una-suba-impositiva

Sainz, A. (2009b, 25 de mayo). Avanza la concentración en el comercio de electrodomésticos. Recuperado de http://www.lanacion.com.ar/1131932-avanza-la-concentracion-en-el-comercio-de-electrodomesticos

Schneider, B. R. (2009). Hierarchical Market Economies and Varieties of Capitalism in Latin America. Journal of Latin American Studies, 41(03), 553575. https://doi.org/10.1017/S0022216X09990186

Schorr, M. \& Gaggero, A. (2016). La cúpula empresaria durante los gobiernos kirchnerista. Realidad Económica, 297, 61-92.

Schorr, M. \& Porcelli, L. (2014). La industria electrónica de consumo en Tierra del Fuego. Régimen promocional, perfil de especialización y alternativas de desarrollo sectorial en la posconvertibilidad. IDAES/UNSAM, Documentos de Investigación Social, (26).

Schvarzer, J. (1978). Estrategia industrial y grandes empresas: el caso argentino. Desarrollo Económico, 18(71), 307-351. https://doi.org/10.2307/3466342

Silva-Colmenares, J. S. (1977). Los verdaderos dueños del país: oligarquía y monopolios en Colombia. Bogotá: Fondo Editorial Suramérica.

Wainer, A. \& Schorr, M. (2006). Trayectorias empresarias diferenciales durante la desindustrialización en la Argentina: los casos de Arcor y Servotron. Realidad Económica, (223).

Wainer, A., \& Schorr, M. (2014). Concentración y extranjerización del capital en la Argentina reciente ¿Mayor autonomía nacional o incremento de la dependencia? Latin American Research Review, 49(3), 103-125. 